\title{
Study on environmental impact of artificial horizontal freezing method in subway connecting passage
}

\author{
Changyi $\mathrm{Yu}^{1,2,3,4}$, Mingyue $\mathrm{Lu}^{5^{*}}$ \\ ${ }^{1}$ CCCC-Tianjin Port Engineering Institute, Ltd., Tianjin 300222, China \\ ${ }^{2}$ CCCC First Harbor Engineering Company, Ltd., Tianjin 300461, China \\ ${ }^{3}$ Key Laboratory of Geotechnical Engineering, Ministry of Communications, Tianjin 300222, China \\ ${ }^{4}$ Key Laboratory of Geotechnical Engineering of Tianjin, Tianjin 300222, China \\ ${ }^{5}$ Tianjin Survey And Design Institute For Water Transport Engineering, Tianjin 300000 , China
}

\begin{abstract}
When the subway is built in complex urban strata, especially when excavating near buildings, it is necessary to strictly control the freezing amount by adopting artificial freezing method. At present, the theoretical calculation is aimed at the frozen rise under ideal conditions, but for complex geological conditions, the simplified model results are difficult to meet the actual requirements. However, numerical calculation can adapt to complex strata and complex boundary conditions. Therefore, in this paper, the environmental impact of artificial horizontal freezing method in subway connecting passage is studied by numerical simulation, and the change of thermophysical parameters with the change of temperature field is considered in the simulation. The simulation method in this paper provides guidance for actual construction.
\end{abstract}

\section{Introduction}

Two centuries ago, the problem of frost heave has attracted the attention of engineering circles, but its frost heave mechanism is not clear. After that, a large number of studies were carried out in academic circles, and it was not realized until more than 50 years ago that the essence of frost heave is water migration. In the 1960s, Everett[1] first put forward the theory of frost heave, which explained the reason of frost heave from the mechanism and derived the value of frost heave from the theory. However, some details have been fully explained, such as how discontinuous lenses are formed in ice after water is frozen. Subsequently, Miller[2] assumed that there is a frozen surface in the frozen material, and there is a phase change zone in front of the frozen surface, which has low water content, low thermal conductivity and no frost heave. This theory also became the second frost heave theory.

Freezing method is also commonly used in shaft excavation. Jessberger H L[3] uses numerical calculation and centrifugal model test to quantitatively study the freezing temperature field and displacement field of shaft, and the results of the two methods are highly consistent, which can provide reference results for related research.

With the development of science and technology, Xray has also been used to detect the position of freezing front. For example, Satoshi Akagawa[4] determined the freezing thickness by improving the test equipment and pressurizing in the sample chamber, and based on this, established the theory of freezing expansion control.
Muto Y and Watanabe K [5] innovatively studied the microstructure change process of freezing front under constant temperature freezing condition. The experiment showed that the greater the freezing thickness, the greater the growth rate of ice lens. Black[6] obtained that the flow of unfrozen water in the phase change zone in front of the freezing front also conforms to Darcy's law through laboratory meso-tests. Japan's Yoshiki Miyata[7] put forward macro frost heave theory based on water migration theory, heat transfer theory and mechanical energy balance equation, which laid a foundation for engineering control of frost heave.

Talamucci[8] proposed to establish a mathematical model of frost heaving in porous media from more comprehensive factors, in which the water migration is due to the coupling effect of chemical potential and pressure gradient, and the model also includes the frost heaving of soil caused by water migration.

In this paper, three-dimensional thermal-mechanical coupling method is used. Firstly, a three-dimensional complex temperature field model is established, and the temperature field is obtained. On this basis, the frozen swelling of soil is calculated. This method can ensure that the thermodynamic and physical parameters of any point of soil change with the change of temperature, which makes the results more accurate.

\section{Numerical model}

The finite element model of frost heave displacement of three-dimensional subway connecting passage is shown in Figure 1. When dividing grids, the grids near the 
connecting channel are dense, and the stress field model and the grids of the temperature field model must be consistent, which requires stress and displacement analysis, so the heat conduction element cannot be used, and the 3D Stress element type should be used instead.

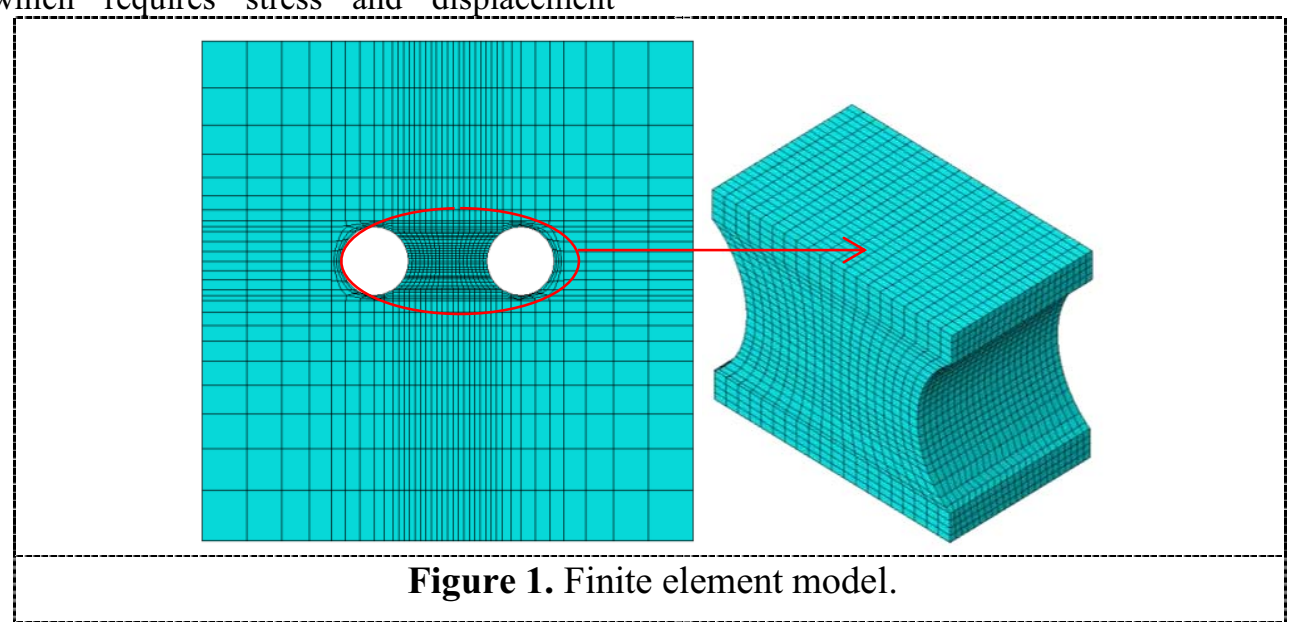

\subsection{Model Parameters}

Three-dimensional frost heaving simulation of

soil parameters are mainly simulated by elastic model, and the stress unit type is C3D8, Calculation parameters and values of frozen expansion are shown in Table 1 connecting channel does not involve soil damage, so the below.

Table 1. Constitutive parameters for frost heave calculation.

\begin{tabular}{ccccc}
\hline $\begin{array}{c}\text { Temperature } \\
{ }^{\circ} \mathrm{C}\end{array}$ & $\begin{array}{c}\text { Density } \\
\mathrm{kg} / \mathrm{m}^{3}\end{array}$ & $\begin{array}{c}\text { Modulus } \\
\mathrm{pa}\end{array}$ & poisson's ratio & $\begin{array}{c}\text { Expansion coefficient } \\
\mathrm{m} / \mathrm{K}\end{array}$ \\
\hline-10 & 1840 & $1.3 \mathrm{E}+08$ & 0.25 & -0.033 \\
-2 & 1883 & $1.05 \mathrm{E}+08$ & 0.28 & -0.021 \\
-1 & 1320 & 20000000 & 0.32 & -0.002 \\
10 & 1364 & 3320000 & 0.34 & 0 \\
\hline
\end{tabular}

\subsection{Boundary Conditions}

The soil is affected by gravity, and there is no load on the surface; The bottom of the soil is completely restrained subway tunnel needs to be completely restrained. The initial temperature field of soil is the temperature field at the beginning of freezing, and the end temperature field is the temperature field at the end of freezing, as shown in Figure 2. in three directions, the four sides of the soil are respectively restrained in the normal direction, and the

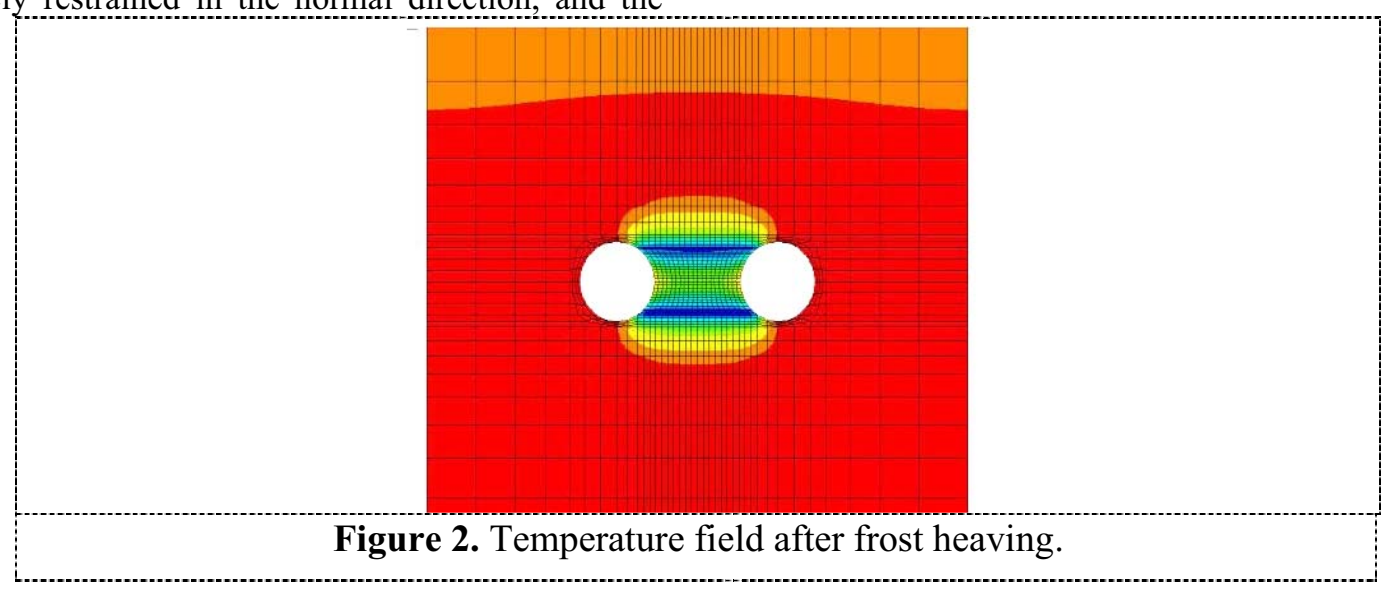

\section{Calculation results}

When there are pipelines near the local surface and subway, frost heave should be considered in the construction of connecting passage freezing method, so it is necessary to investigate the frost heave in the surface and stratum. The numerical simulation results for these two problems are as follows: 

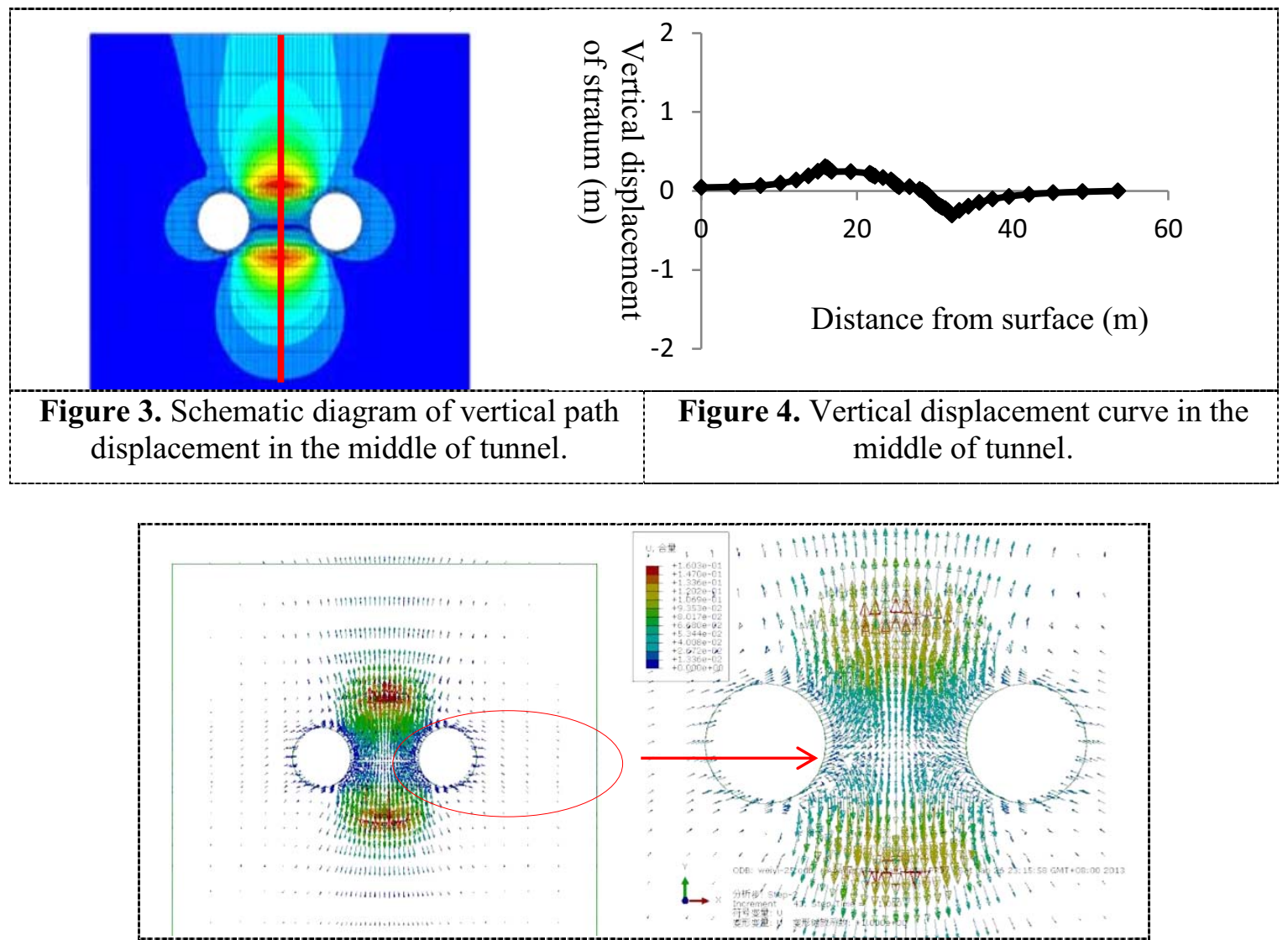

Figure 5. Displacement vector diagram of middle vertical section of tunnel.

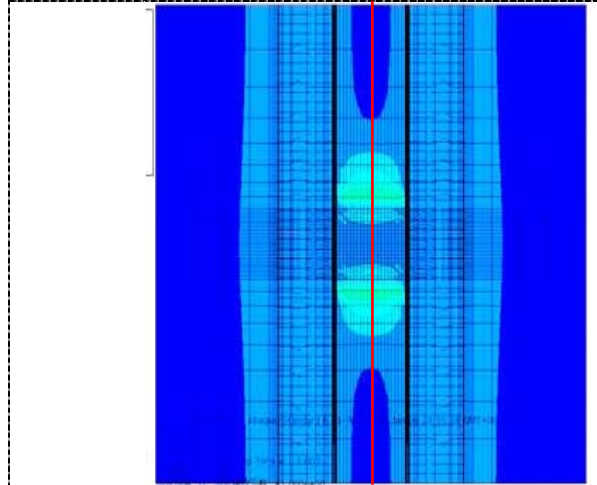

Figure 6. Horizontal displacement of middle horizontal path of tunnel.

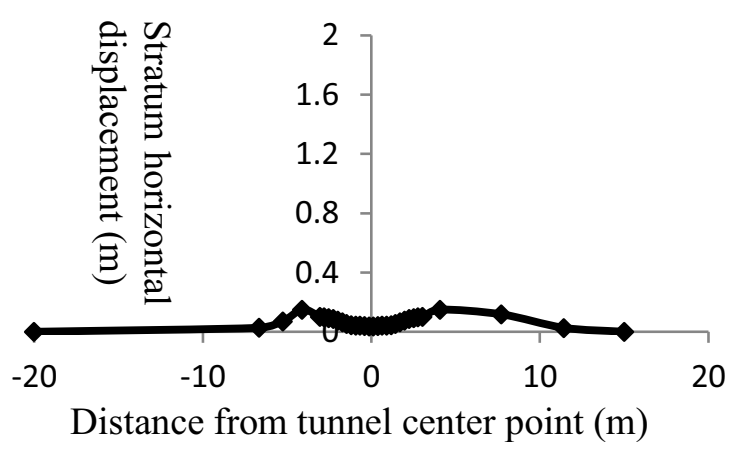

Figure 7. Horizontal displacement curve along middle of tunnel.
It can be known from figure 4 and figure 7 that during the freezing process, the displacement of soil frost heave inside the horizontal freezing curtain, that is, in the middle of the communication channel, is small, while the displacement of soil frost on both sides of the horizontal freezing curtain of the communication channel increases first and then decreases. 


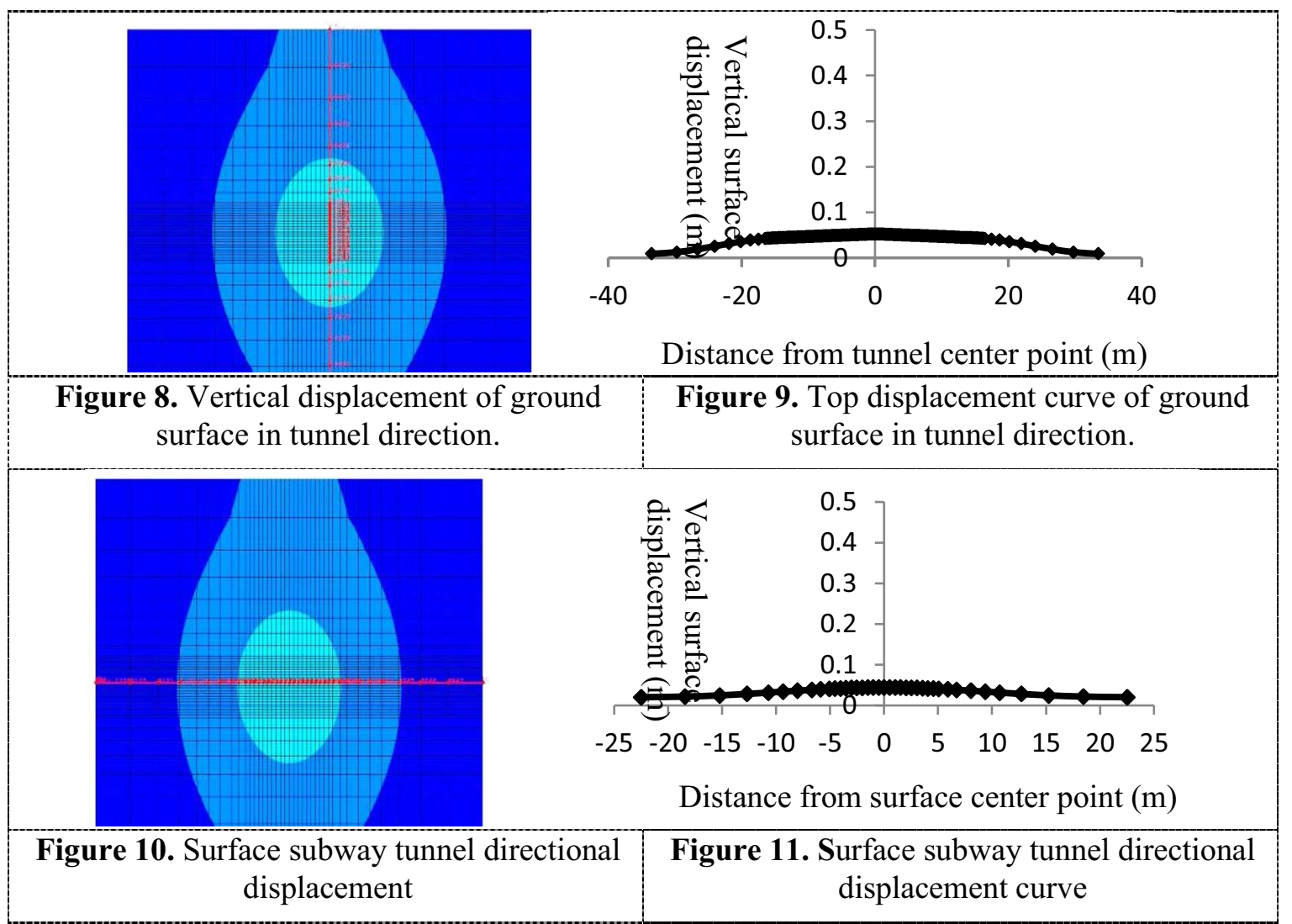

It can be known from figure 9 and figure 11 that the vertical displacement directly above the ground surface in the horizontal freezing area of the communication channel is up to $5 \mathrm{~cm}$, and the displacement away from the area directly above the freezing area is getting

smaller and smaller, where the freezing temperature is 25 degrees, the maximum value of the frozen expansion coefficient is $3.4 \%$, and its influence area exceeds $45 \mathrm{~m}$ along the freezing pipe direction and $25 \mathrm{~m}$ along the tunnel direction.

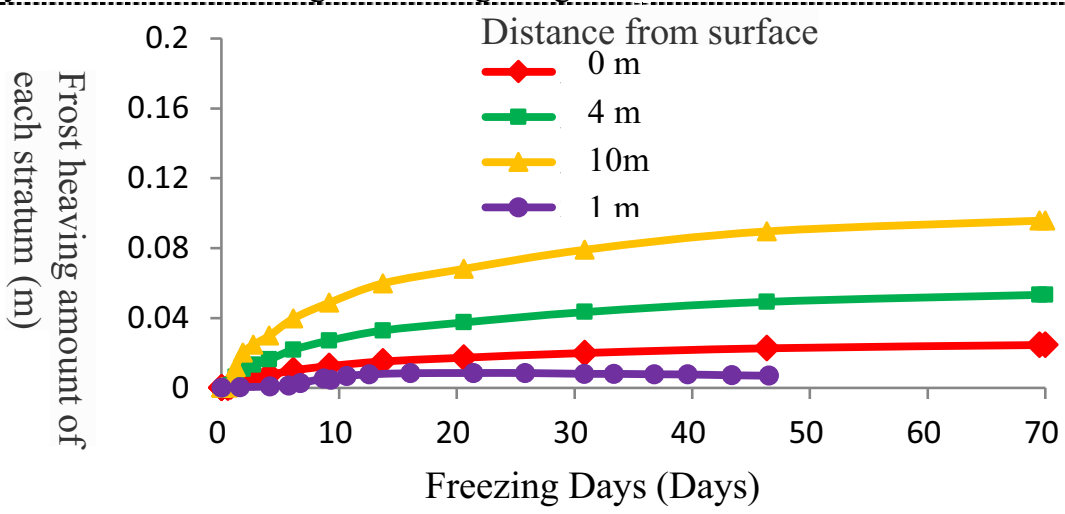

Figure 12. Comparison between finite element calculation and actual measurement

It can be seen from figure 12 that the measured frost heave displacement is basically consistent with the frost heave obtained by finite element simulation, which shows that the indirect thermal coupling method adopted in this paper is reliable, and can be used for reference in design and construction, and also lays a foundation for subsequent control of frost heave.

\section{Conclusion}

During the process of soil freezing, soil expansion will change the stress field of soil in its original state. When there are buildings around the freezing construction and the maximum displacement of soil frost heave is limited, it is necessary to control the frost heave range and amount of soil frost heave to ensure that the freezing construction will not have destructive influence on the surrounding area. In this paper, a three-dimensional thermo-mechanical coupling numerical model is used to simulate the frozen displacement field of the stratum when a subway connecting passage is frozen horizontally. The results show that the displacement near the frozen wall is larger, and the frozen surface is the largest just above the frozen area, and gradually decreases around. The results of this paper provide reliable and effective reference and guidance for design and construction. 


\section{References}

1. Yunhui Y, Ping Y, Haibo W. Thermal field numerical analysis of artificial thawing of horizontal freezing soil wall[J]. Journal of Nanjing Forestry University(Natural Sciences Edition), 2011.

2. Ting-Hong Z, Dong W, Gui-Quan B I, et al. Numerical analysis of ground thaw subsidence caused by artificial horizontal ground freezing $[\mathrm{J}]$. Journal of Lanzhou University of Technology, 2014.

3. [3] Xiao-Bin W, Ping Y, Ting Z, et al. 3-D finite element analysis of melting temperature field in hield tunneling horizontal freezing reinforcing engineering[J]. Journal of Pla University of ence \& Technology, 2009.

4. Bhardwaj S, Singh S K. Model study and 3-D numerical analysis of vertical micropile subjected to oblique pullout loads[J]. International journal of geotechnical engineering, 2017, 11(4):405-417.

5. Hall, Douglas Ralph. Numerical Solutions of Nonlinear Free-Surface Wave Problems (Numerical Analysis, Filtering, Artificial Viscosity)[J]. 1984.

6. Feng-Tian Y, Pei-Yun Q, Guo-Xiang Y, et al. Numerical calculation of tunnel cross passage construction underneath river[J]. Journal of China Coal Society, 2005.

7. Hu X D, Ji B Y . Optimization of Double-RingPipe Freezing Scheme for Tunnel Cross-Passage Construction[J]. Advanced Materials Research, 2012, 446-449:2262-2266.

8. Weng Jiajie, Zhang Ming. SIMULATION AND OPTIMIZATION FOR THERMAL SYSTEM IN GROUND ARTIFICIAL FREEZING[J]. Journal of China University of Mining and Technology: English Edition, 1990. 